\title{
Removal of contaminants in indoor air by using green plant treated with titanium dioxide nanoparticles
}

Khaled Fikry salama ( $\sim$ ksalama@iau.edu.sa )

Imam Abdulrahman Bin Faisal University https://orcid.org/0000-0001-9115-8644

Mubashir Zafar Zafar

Imam Abdulrahman Bin Faisal University

\section{Research article}

Keywords: Titanium dioxide, Green plant, Air contaminants, Mytrus Communis, Indoor air, toxic gases.

Posted Date: September 3rd, 2019

DOI: https://doi.org/10.21203/rs.2.11822/v1

License: (c) (i) This work is licensed under a Creative Commons Attribution 4.0 International License.

Read Full License 


\section{Abstract}

Background: Indoor air pollution is important environmental health problem. Nanotechnology is one of the most important methods to reduce the air pollution. The aim of this study to determine the effectiveness of nanotechnology for removal of toxic air indoor pollution by using Saudi myrtle plants treated with titanium dioxide. Methods: Experiments were conducted in the two academic departments of labs at public sector universities. Aplying titanium dioxide-containing growth media to at least one of a Myrtus communis plant root, stem, and leaf. Growing the plant in the growth media, a gel growth media, or both; exposing the plant to contaminant-containing air Results: It is found that the levels of formaldehyde, Volatile organic compounds and other pollutants were significantly reduced the concentration from $10 \%$ to $98 \%$ in air. The duration of the intervention from 4 hours to 8 hours, Air containing the concentration of NO2 SO2, formaldehyde, TVOCs and CO reduced from range of $0.3 \mathrm{ppm}$ $0.4 \mathrm{ppm}$ to range of $0.1 \mathrm{ppm}-0.3 \mathrm{ppm}$ after exposure of Myrtus plant to ambient air and duration of the exposure is 4 hours to 8 hours. Conclusion: Application of Tio2 in green plant specially Mytrus Communis is a novel approach for reduction of concentrations of harmful gaseous toxic and carcinogenic air pollutants in indoor environment.

\section{Background}

Environmental pollution is important public health problem. ${ }^{1}$ Indoor air environment has high level of toxic pollutant and most common places were affected public places such as homes, schools, offices, hospitals. ${ }^{1}$ In developed countries peoples were spent most of the time in indoors, which was exposed to polluted air that may result to adverse health effects. There are various health effects from mild disease to carcinogenic effects on human body due to this toxic air pollutants. ${ }^{2}$ the most common hazards are formaldehyde, volatile organic compounds, $\mathrm{SO} 2, \mathrm{NO} 2, \mathrm{CO}^{3}$

Nitrous oxide and (NOx) and Volatile organic compounds (VOCs) are group of air contaminants that deteriorate the air quality either in indoor environment. Benzene, toluene, ethylbenzene, and Xylene (BTEX) are important component of VOCs and NOx. NOx and Volatile organic compounds have carcinogenic abilities, which produce various cancers in the human body. It has also causes different respiratory disease such as COPD, asthma and various eyes, skin and neurological disorders. ${ }^{4}$

There are various methods to reduced the toxic components of air and most common method is photo catalytic oxidation of organic matter which removes air contaminants from air. ${ }^{5} \mathrm{TiO} 2$ is generally accepted as one of the most effective photo induced catalysts and it is frequently used to oxidize organic and inorganic compounds in air due to its strong oxidative ability and long-term photo-stability. ${ }^{6}$ Titanium dioxide nanoparticles had photo catalytic properties in which ultra violet (UV) light can oxidize organic air contaminants which is commonly present in air. It has also effectively used to reduce VOCs and NOx . ${ }^{7}$ TiO2 is relatively cheap, has fast reaction rates, and can convert a wide range of organic compounds. 
These properties make $\mathrm{TiO} 2$ the ideal photo catalyst to incorporate onto existing infrastructure for improved air quality. ${ }^{8-9}$

Educational institutions are the building block of any country because young people were trained and they become future leaders of nations. Environment in universities affected the health of students, if they exposed continues to pollute air, various health disorders among young people. There are various adverse health disorders such as fatigue, respiratory disorders which lead to bad performance of staff and students. Laboratories are special microenvironments in university buildings where pollutant concentrations were high due. ${ }^{10-11}$

Photo catalytic oxidations processes were used effectively in indoor air purification by get rid of gaseous pollutants. Hydroxyl and superoxide radicals were produced and after oxidation of the VOCs into CO2, water, and some intermediate compounds which will be used as air contaminates removers. ${ }^{12-13}$

Myrtus communis is evergreen tree with dense flora for the Mediterranean regions and Middle East nations. This region's has mostly sunny and humid weather which is perfect for cultivation of this tree. ${ }^{14}$ Plants absorb carbon dioxide in air, assimilate the carbon dioxide via photosynthesis, and release oxygen. ${ }^{15}$ Plants have the capability to remove volatile organic compounds (VOCs) from air. ${ }^{16}$ Plants that improve air quality are widely used in facilities (e.g., hospitals and universities), offices, and different other public places. ${ }^{17}$ The air quality-improving effect of plants having foliage (i.e., "foliage plants") which improved by promoting photosynthesis. ${ }^{17}$

Myrtus communis tree with TiO2 concentrations as controller for the indoor air contaminants are not significantly tested for removal of toxic air contaminates. In this study, indoor air quality (IAQ) was investigated in research laboratories of two departments at a university. Formaldehyde, VOC (volatile organic compounds), $\mathrm{NO} 2$ and SO2 and $\mathrm{CO}$ concentrations were measured in presence and absence of myrtle plants treated with known concentration of titanium dioxide. Indoor environmental comfort which is defines as air change per hour (ACH) temperature and relative humidity. It was measured after treatment of myrtle plants with titanium dioxide.

The main aim of the study is to determine the effectiveness of myrtle plants which was treated with titanium oxide to reduce the indoor air pollution around teaching laboratories.

\section{Methods}

The study was conducted in the two different academic department of public sector university. Study design was experimental.

\section{Indoor air Quality assessment:}

The experiment was conducted over 5 working days in the selected laboratories where day I data were recorded without use of $\mathrm{TiO} 2$ nano-particles $\left(\mathrm{TiO}_{2} \mathrm{NPs}\right.$ ) and day 2 to 4 days $\mathrm{TiO}_{2}$ nanoparticles (NPs) 
was applied in different concentrations with similar experiment setting. Multiple readings were recorded during 8 hours duration. Every hour reading was calculated and the end of the day average reading was calculated.

\section{Preparation of TIO2 nanoparticles:}

TiO2 NPs(nanoparticles) P25 (80\% anatase, 20\% rutile, Sigma-Aldrich, USA, Art. No. 718467) were prepared in different concentrations as $1,3,5,7, \mathrm{ppm}$ in water suspension after sonication. Different concentrations of TiO2 nanoparticles $(40-10 \mathrm{~nm}$ ) were prepared and applied to the Myrtus communis $\mathrm{L}$ plant. The growth media was prepared with TiO2 and this media applied to plant root, stem and leaf. The growth media has a concentration of titanium dioxide in the range of $0.5 \mathrm{ppm}$ to $10 \mathrm{ppm}$. Myrtus plant exposed to indoor air.

\section{Procedure of Intervention}

There are two groups, one group where plant were exposed to air without the use of $\mathrm{TiO} 2$ nanoparticles and other group where plant with $\mathrm{TiO} 2$ nanoparticles were exposed to air, this group have sub categories such as different concentration of TiO2 applied to plant and then exposed to indoor air. Over 8-hour periods, multiple readings were recorded every one hour and at the end of the day average reading was calculated for whole day.

The data were collected under controlled levels of humidity, temperature, and air flow exchange.

\section{Measurements of gaseous air pollutants}

Gaseous air contaminants $\mathrm{CO}$, VOCs, Formaldehyde, sulphur dioxide $\left(\mathrm{SO}_{2}\right)$, nitrogen dioxide $\left(\mathrm{NO}_{2}\right)$ were measured in different location around the selected location. The temperatures, air speed, relative humidity were also recorded with the measurement of air contaminants using special Kestrel 4500 equipment.

\section{Levels of all gaseous air pollutants}

Levels of the selected gaseous air pollutant were measured directly by the Gray Wolf's Directness mobile PC based products advanced Sense TM with Wolf Pack TM area monitor. This monitor is composed of multi gas detectors equipped with a wireless radio frequency modem which allows the unit to communicate and transmit readings and other information on a real-time basis with a remotely located base controller.

At each measuring point, several readings in parts per million $(\mathrm{ppm})$ were recorded for each gaseous pollutant during the two-hour period (a reading per 15-30 min). For quality assurance, the instruments were calibrated and adjusted to record and save directly to main monitor.

\section{Results}


The 8-hour average levels of total volatile organic compounds (VOCs) indoor air with intervention of TiO2 was represented in Fig. 1, and the 8-hour average levels of formaldehyde indoor air with intervention of TiO2 was represented in Fig. 2.

The mean level of volatile organic compounds (VOC) and formaldehyde indoor air in different days without interventions of $\mathrm{TiO} 2$ was represented in Fig. 3

The mean level of NO2, SO2 and $\mathrm{CO}$ in indoor air with intervention of TiO2 was represented in Fig. 4

The mean level of NO2, SO2 indoor air without intervention of TiO2 was represented in Fig. 5

The concentration of volatile organic compound and formaldehyde were reduced in the air as TiO2 exposure increased from $1 \mathrm{ppm}$ to $7 \mathrm{ppm}$. The concentration of VOC reduced from 410 to 54 and the concentration of formaldehyde was reduced from 0.27 to $0.014 \mathrm{ppm}$. The variation of air change per hour and others factors as temperature, humidity, air velocity were not significantly changed. (Table 1)

The toxic concentration of $\mathrm{CO}, \mathrm{NO} 2$ and SO2 were reduced from 1.5 to $0.01,0.041$ to 0.0003 and 0.009 to 0.0003 respectively with increasing the concentrations of $\mathrm{TiO} 2$ from $1 \mathrm{ppm}$ to $7 \mathrm{ppm}$ in regard to minor variation of air change per hour rate, temperature, humidity and air velocity. Table (2) and Figure (4)

\section{Discussion}

The result of this study was found that Photo catalytic oxidation (PCO) is effective method for reducing the toxic contaminates in indoor air common air pollutants were significantly reduced after intervention with nanotechnology. Coating a photo catalyst, e.g., commercial P25 TiO2, onto a substrate and irradiating it with UV light is the most popular method for purification of indoor air. ${ }^{17}$

This study result has found that the NO concentration reduced to $50 \%$ in air and this result has consistent with other studies ${ }^{18}$. A previous study using $\mathrm{TiO} 2$ to coat an activated carbon filter found that the NO reduced to $66 \%$, and benzene, toluene, ethyl benzene, and xylene (BTEX) were removed by more than $60 \%{ }^{19}$. In other study, toluene removal efficiency was increased from $32 \%$ to $78 \%$ when using a combination of Photo catalytic oxidation 20-22

The result found that Carbon monoxide was significantly reduced after the intervention with TiO2. This result was consistent with the previous study which was conducted in developing country shows that $60 \%$ reduction of $\mathrm{CO}^{23}$. The source of gaseous pollutants such as Nitrogen, Carbon and Sulpher Oxides are from various commercial and industrial units due to the uses fossil fuels as power generations. ${ }^{24}$ It is concern for environmental experts that there is need for alternative for fossil fuels which counter the hazards of fossil fuels, it helps for implementation of global environment sustainability. ${ }^{24}$

Result found that VOC concentration significantly reduced which is same as previous study. 
The previous study found that VOC concentration was reduced $40 \%{ }^{25}$ The burning of fuels such as gasoline, wood, coal, or natural gas is the main contributor to global VOC emissions. ${ }^{25-27}$ Titanium dioxide is incorporated into various types of coatings which can be applied in many situations as an effective tool to remove volatile organic compounds (VOCs) and other toxic compounds from the surrounding environment, among other benefits. ${ }^{28-29}$

This is the unique study which showed that indoor air pollution will be controlled by nanotechnology. It is recommended that commercial used of this technology especially industry which helps to improve the indoor air quality. Limitation of this study is it was conducted in educational institution; there is need of larger experimental study to be conduct in big commercial offices to monitor the effectiveness of nanotechnology.

\section{Conclusion}

Application of Tio2 in green plant specially Mytrus Communis is a novel approach for reduction of concentrations of harmful gaseous toxic and carcinogenic air pollutants in indoor environment.

\section{Abbreviations}

$\mathrm{NO}_{2}$. Nitrous dioxide

$\mathrm{SO}_{2}$. Sulphur dioxide

VOC. Volatile organic compound

CO. Carbon oxide

Ppm. part per million

$\mathrm{TiO}_{2}$. Titanium dioxide

PM. Particulate Mater

$\mathrm{NO}_{\mathrm{X}}$. Nitrous Oxide

BTEX. Benzene, Toluene, ethylbenzene, xylene

UV. Ultraviolet

IAQ. Indoor for quality

$\mathrm{ACH}$. Air change per hour

NPs. Nanoparticles 


\section{Declarations}

\section{Ethics approval and consent to participate}

The study was approved by ethical committee of Imamm Abdul Rehman bin Faisal University. Consent to participate not applicable because no study participants.

\section{Consent Publication}

Not applicable

\section{Availability of data and materials}

The dataset generated and / or analysed during the current study are not publicly available due to data in the custody of university administration but are available from the corresponding author on reasonable request.

\section{Competing interests}

There is no competing interest financial and non financial between the authors.

\section{Funding}

The authors would like to thank Deanship of scientific research at Imam Abdulrahman Bin Faisal University for the financial support given during this study, which was a part of the research project No. 2017-411-CPH

The research project was published as US patent with number: US 2018/0279623 A1 date Oct. 4, 2018 And granted from US patent with grant number: US 10,244,764 B2 date, Apr. 2,2019

\section{Authors Contributions}

KS the correspondence author conceived the concept and design, data collection, data interpretation. He drafted the manuscript and revised the article. MZ revised and proof reading.

\section{ACKNOWLEDGMENT}

The authors would like to thank Deanship of scientific research at Imam Abdulrahman Bin Faisal University for data collection.

\section{References}

1. S. Wang, H.M. Ang, M.O. Tade. Volatile organic compounds in indoor environment and photocatalytic oxidation: state of the art, Environ. Int. 33 (2007)694-705 2. K. De Witte, V. Meynen, M. Mertens, O.I. 
Lebedev, G. Van Tendeloo, A. Sepulveda-Escribano, et al. Multi-step loading of titania on mesoporous silica: influence of the morphology and the porosity on the catalytic degradation of aqueous pollutants and VOCs, Appl. Catal. B: Environ. 84 (2008) 125-132. 3. Jones, A.P. Indoor air quality and health. Atmospheric Environment. 1999 33: 4535-4564. 4. Park, J., Lee,L., Byun, H., Ham, S., Lee, I., Park, J., Rhie, K., Lee, Y., Yeom, J.,Tsai, P., Yoon, C., . A study of the volatile organic compound emissions at the stacks of laboratory fume hoods in a university campus. Journal of Cleaner Production. 201466: 10-18. 5. Alshuwaikhat H.M. and Abubakar I.,. An integrated approach to achieving campus sustainability: assessment of the current campus environmental management practices. Journal of Cleaner Production. 200816: 1777-1785. 6. Strini A, Cassese S, Schiavi L.,. Measurement of benzene, toluene, ethylbenzene and 0 -xylene gas phase photodegradation by titanium dioxides dispersed in cementitious materials using a mixed flow reactor. Appl Catal B-Environ.2005;61:90-7. 7. Ochiai T, Fujishima A Photoelectrochemical properties of TiO2 photocatalyst and its applications for environmental purification. J Photochem Photobiol C Photochem Rev. 201213:247-62. 8. Fujishima, A., and X. Zhang. . "Titanium Dioxide Photocatalysis: Present Situation and Future Approaches". 2006: 750-760. 9. Hassan,M. M., H. Dylla, L.N. Mohammad, and T. Rupnow. . "Effect of Application Methods on the Effectiveness of Titanium Dioxide as a Photocatalyst Compound to Concrete Pavement." Paper presented at the 89th Transportation Research Board Annual Meeting. 2010 10. Hussin, M. et al., Air-conditioned university laboratories: Comparing $\mathrm{CO} 2$ measurement for centralized and split-unit systems. Journal of King Saud UniversityEngineering Sciences(2014), http://dx.doi.org/10.1016/j.jksues.2014.08.005 11. Godwin, C., Batterman, S., . Indoor air quality in Michigan schools. Indoor Air. 200717:109-121. 12. Sofuoglu, S.C., Aslan, G., Inal, F., Sofuoglu, A.,. An assessment of indoor air concentrations and health risks of volatile organic compounds in three primary schools. International Journal of Hygiene And Environmental Health. 2011214 :38-46. 13. ASHRAE Standard 62-2007. Ventilation for acceptable indoor air quality. Atlanta: American Society of Heating and Refrigerating and Air-Conditioning Engineers Inc. 14. Xingmao Ma, Jane Geiser-Lee, Yang Deng , Andrei Kolmakov. Interactions between engineered nanoparticles (ENPs) and plants: Phytotoxicity, uptake and accumulation, Sci Total Environ. 2010: 1-9 15. Ochiai T, Fujishima A. Photoelectrochemical properties of TiO2 photocatalyst and its applications for environmental purification. J Photochem Photobiol C Photochem Rev. 2012;13: 247-62. 16. Rackes, A., Waring, M.S.,. Using multi objective optimizations to discover dynamic building ventilation strategies that can improve indoor air quality and reduce energy use. Energy Building . 2014; 75: 272-280 17. Sulaiman Z and Mohamed M,. Indoor air quality and sick building syndrome study at two selected libraries in Johor Bharu, Malaysia, Environment Asia. 2011 4(1): 67-74. 18. Syazwan, A.I., Juliana, J., Norhafizalina, O., Azman, Z.A., Kamaruzaman, J. Indoor air quality and sick building syndrome in malaysian buildings. Global Journal of Health Science. 2009;1 (2): 126-135. 19. Toprak, M., Gursoy, G., Demiral, Y., Cimrin, A.H., Sofuoglu, S. Indoor Air quality and occupational risk factors in university laboratories. Hava Kirliligi Arastirmalari Dergisi . 2013;2: 87-95. 20. USEPA, 2003. An office building occupant's guide to indoor air quality. US Environmental Protection Agency, USA. 21. Han Z, Chang VWC, Zhang L, Tse MS, Tan OK, Hildemann LM Preparation of TiO2-coated polyester fiber filter by spray-coating and its photocatalytic degradation of gaseous formaldehyde. Aerosol Air Qual Res . :2012;12: 1327-35. 22. Mendes A, Pereira C, Mendes D, Aguiar L, Neves P, Silva S, Batterman S, Teixeira JP. Indoor air quality and thermal comfort- 
results of a pilot study in elderly care centers in portugal. J Toxicol Environ Health A .2013;76(4-5):333344. 23. Song JE, Kim YS, Sohn JY. The impact of plants on the reduction of volatile organic compounds in a small space. J Physiol Anthropol .2007: 22 (6):599-603 24. Wood RA, Orwell RL, Tarran J, Torpy F, Burchett M: Potted-plant/growth media interactions and capacities for removal of volatiles from indoor air. Journal of Horticultural Science and Biotechnology. 2002: 77(1):120-129. 25. Orwell RL, Wood RA, Tarran J, Torpy F, Burchett MD: Removal of benzene by the indoor plant/substrate microcosm and implications for air quality. Water Air Soil Pollut .2004: 157:193-207. 26. Alessio G A, De Lillis M, Fanelli $\mathrm{M}$, Pinelli $\mathrm{P}$ and Loreto $\mathrm{F}$. Direct and indirect impacts of fire on isoprenoid emissions from Mediterranean vegetation. Functional Ecology.2004:18 : 357-364 27. Bita C E and Gerats T . Plant tolerance to high temperature in a changing environment: scientific fundamentals and production of heat stress-tolerant crops. Front Plant Science $2013: 4$ doi:10.3389/fpls.2013.00273 28. Çakir A . Essential oil and fatty acid composition of the fruits of Hippophae rhamnoides L. (Sea Buckthorn) and Myrtus communis L. from Turkey. Biochemical Systematics and Ecology. 2004:32 : 809-816 29. Yau Y.H, Chew B.T., Saifullah A.Z.A. Studies on the indoor air quality of Pharmaceutical Laboratories in Malaysia, International Journal of Sustainable Built Environment, 20121(1): 110-124

\section{Tables}

Due to technical limitations, tables are only available as a download in the supplemental files section.

\section{Figures}

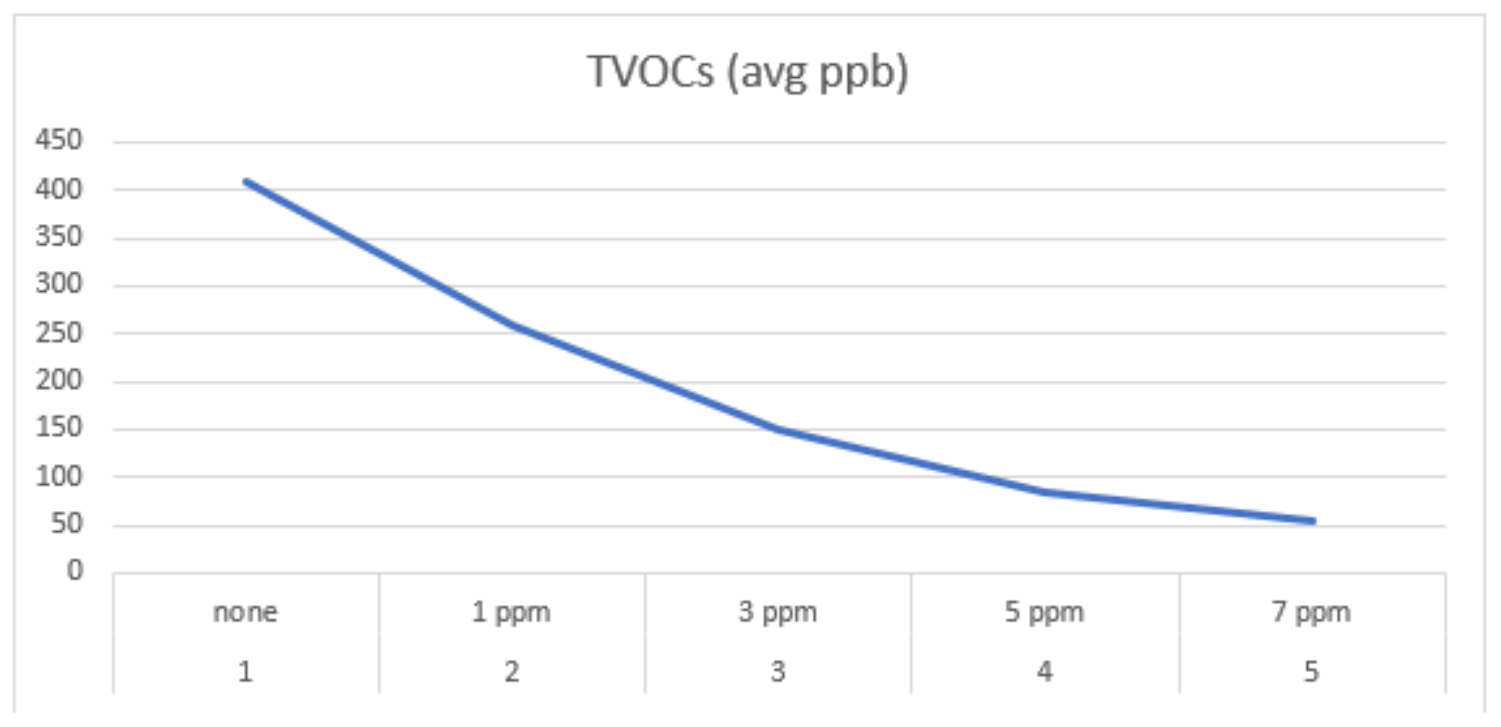

Figure (1): Mean levels of TVOCs removed by Myrtus communis treated with different concentrations of $\mathrm{TiO}_{2}$ 
Mean levels of TVOCs removed by Myrtus communis treated with different concentrations of TiO2

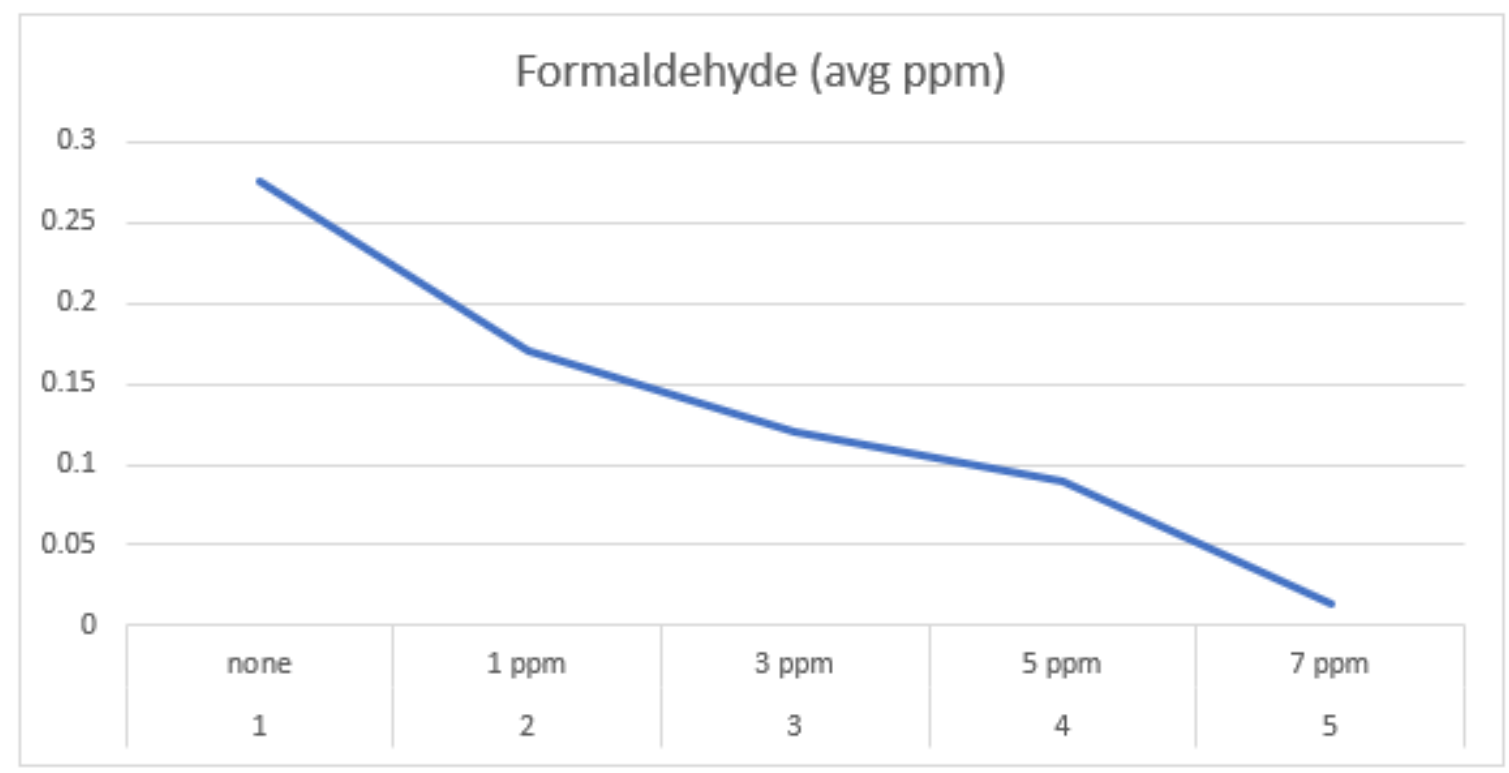

Figure (2): Mean levels of formaldehyde removed by Myrtus communis treated with different concentrations of $\mathrm{TiO}_{2}$

\section{Figure 2}

Mean levels of formaldehyde removed by Myrtus communis treated with different concentrations of TiO2

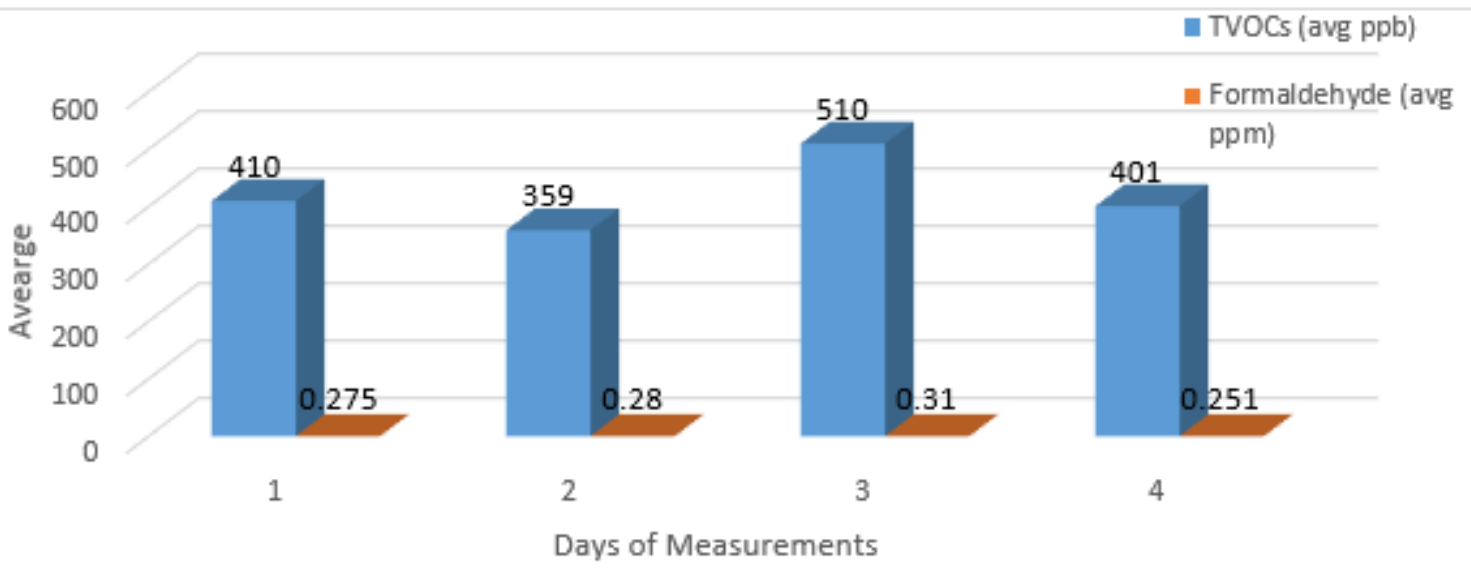

Figure (3): Mean levels of TVOCs and Formaldehyde in absence of Mytrus treated with different concentrations of $\mathrm{TiO} 2$ nanoparticle (Control Conditions)

\section{Figure 3}


Mean levels of TVOCs and Formaldehyde in absence of Mytrus treated with different concentrations of TiO2 nanoparticle (Control Conditions)

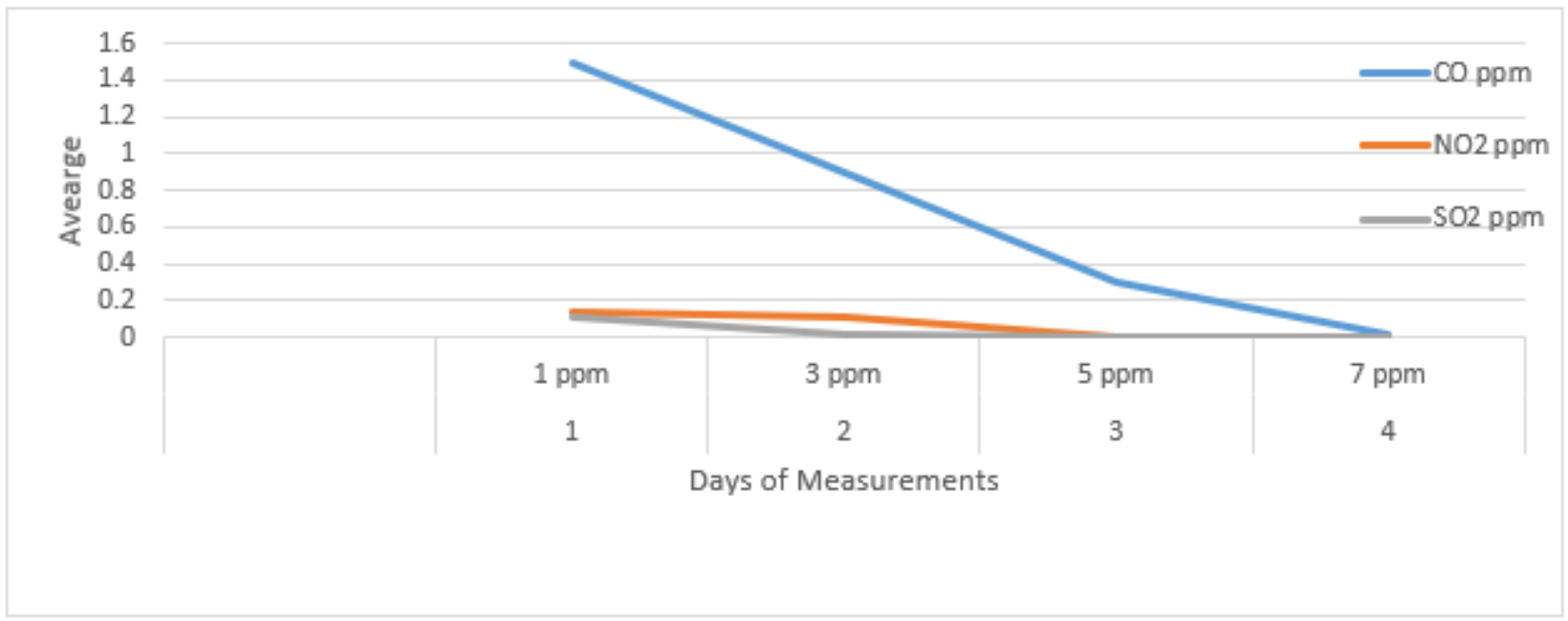

Figure (4): Mean levels of gaseous air pollutants $\left(\mathrm{CO}, \mathrm{NO}_{2}\right.$ and $\left.\mathrm{SO}_{2}\right)$ removed by Myrtus communis treated with different concentrations of $\mathrm{TiO}_{2}$

\section{Figure 4}

Mean levels of gaseous air pollutants (CO, NO2 and SO2) removed by Myrtus communis treated with different concentrations of $\mathrm{TiO} 2$

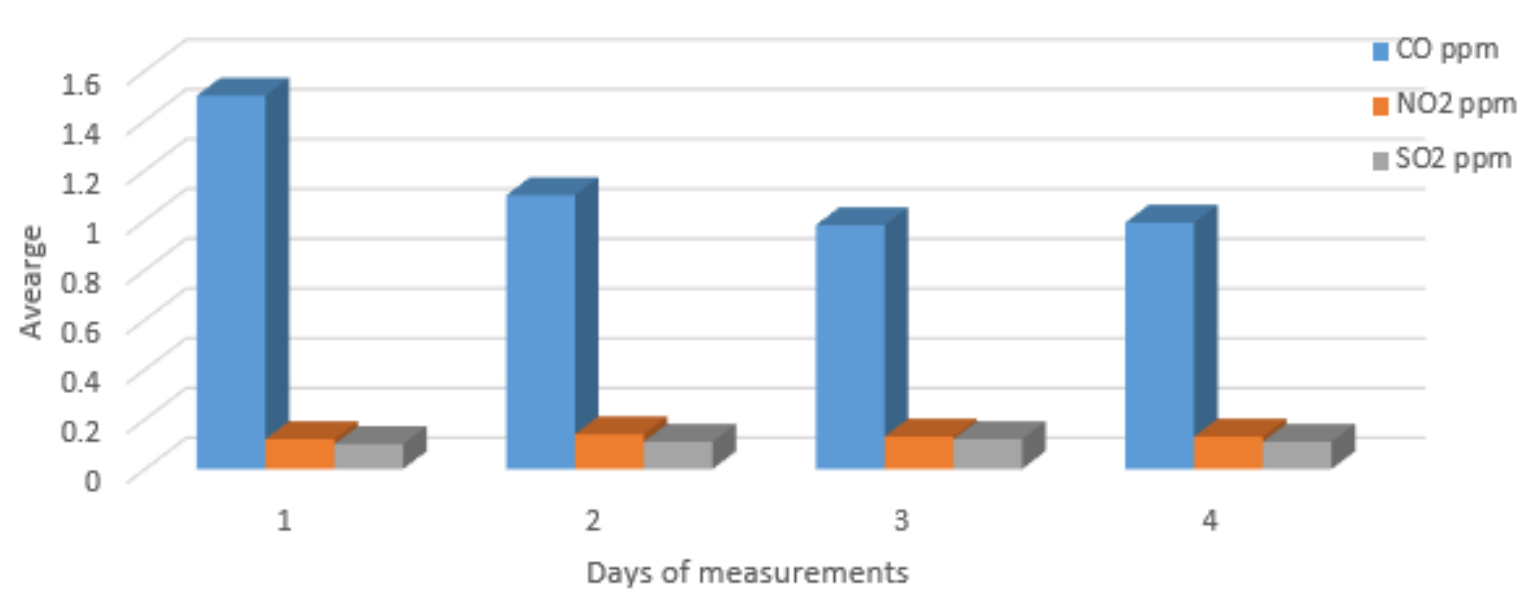

Figure (5): Mean levels of Carbon monoxide, Nitrogen dioxide and Sulphur dioxide in absence of Mytrus treated with different concentrations of $\mathrm{TiO}_{2}$ nanoparticle (Control) 
Figure 5

Mean levels of Carbon monoxide, Nitrogen dioxide and Sulphur dioxide in absence of Mytrus treated with different concentrations of TiO2 nanoparticle (Control)

\section{Supplementary Files}

This is a list of supplementary files associated with this preprint. Click to download.

- Tables1and2.pdf 